\title{
Automatic Lineaments Extraction using the Line Algorithm in the Denguélé District (North West of Ivory Coast)
}

\author{
Pinatibi, H., ${ }^{1 *}$ Coulibaly, T. J. H. ${ }^{2}$ and Soro, M. ${ }^{1}$ \\ ${ }^{1}$ Department of Fundamental Applied Sciences, mathematics and computer science Laboratory, Nangui \\ Abrogoua University, Côte d'Ivoire, 01 PO Box 802 Abidjan 01 \\ E-mail: pinatibih@gmail.com, sorosocialiste@mail.ru \\ ${ }^{2}$ Department of Environmental Sciences and Management, Geosciences and environment \\ Laboratory, Nangui, Abrogoua University, Côte d'Ivoire, 01 PO Box 802 Abidjan 01, \\ E-mail: ctalnan@yahoo.fr \\ *Correspondence Author \\ DOI: https://doi.org/10.52939/ijg.v17i6.2065
}

\begin{abstract}
The aim of this work was to apply the LINE Algorithm (Segment Extraction Algorithm) on Landsat 8 images for automatic lineament extraction in the Denguéle district. The Landsat 8 images had previously been subjected to the technique of Principal Component Analysis (PCA). After that, we implemented the LINE algorithm. Indeed, the LINE algorithm uses the following six (6) parameters : RADI (Radius of the filter) for improving the quality of the input image, GTHR (Threshold of the contour gradient), LTHR (Threshold of the contour length), FTHR (Threshold of mounting error), ATHR (Angular difference threshold between two contours ) and DTHR (Distance chaining threshold to link two contours ) for lineament discrimination. Analysis of the principal components PCA 1, PCA2 and PCA3 of bands 1,2, 3, 4, 5 and 7 of the Landsat 8 images shows that they contain respectively 79.57; 15.88 and $2.15 \%$, this represents overall $97.6 \%$ of all channels. 3468 lineaments were extracted. The minimum and maximum lengths of the lineaments extracted are respectively $4201.08 \mathrm{~m}$ and $16167.59 \mathrm{~m}$ and their cumulative length is $18919517.9 \mathrm{~m}$. The lineaments average lengths are $5.55 \mathrm{~km} ; 5.75 \mathrm{~km} ; 5.6 \mathrm{~km}$ and $5.40 \mathrm{~km}$ respectively for NE-SW, NS, E-W and NW-SE directions. The analysis of the directions of the lineaments using a rose diagram with $10^{\circ}$ of frequency, shows that the dominant directions are NE-SW (31.83\% of the total lineaments), EW (28.71\% of the total lineaments) and NS (27.91\% of the total lineaments).
\end{abstract}

\section{Introduction}

The term lineament is related to several physical realities, which are among others hydrogeology (Detection of areas favorable to the establishment of boreholes), urban transport (roads and railways), town planning (construction of dams, bridges etc.) and also for the assessment of seismic and landslide risks (Stefouli et al., 1996). Thus, several authors have given a definition to this notion. According to Hobbs (1904) the notion of lineament is one of the most commonly used terms in geology. A lineament is any extended linear surface on a planet, such as a fault line or a fracture line. O'Leary et al., (1976) described the term lineament as a mappable, simple or composite linear entity of a surface whose parts are aligned in a rectilinear or slightly curvilinear relationship and which differs from the pattern of adjacent elements and presumably reflects some subsurface phenomenon. According to the NASA website, the term lineament has been defined under several aspects which are aerial imagery, geology, geography and town planning, thus the term lineament refers to all linear features that can be selected as lines (appearing as such or obvious due to contrasting terrain or ground cover on either side) in aerial or spatial imagery (https://www.nasa.gov/). From a geological point of view, lineaments are generally faults, joints or boundaries between stratigraphic formations. Finally, in the fields of geography and town planning, lineaments include roads and railways, contacts accentuated by the contrast between natural or artificial geographical features (fences) (https://www.nasa.gov/).

In view of the importance and interdisciplinary nature of this notion, the manipulation of lineaments 
is of great importance in research. Thus, several lineament characterization methods have been used by the researchers. The first studies used manual analytical methods. The extraction of lineaments was attempted from aerial photographs as well as satellite images, in the form of a discontinuity of darker or lighter color in differentiation with the surrounding area. These linear anomalies were detected by manual interpretation followed by certain image processing techniques such as image rationing, image fusion, directional edge detection filtering (Prasad et al., 2013 and Morris, 1991). In view of the limitations observed in the application of manual methods (tedious, imprecise operation, etc.), new approaches based on the use of computer algorithms are increasingly used. Various researchers have worked on this (computer algorithms) with various inputs. Some work has been tried on a recent optical imaging satellite like Landsat-8 OLI (Ibrahim and Mutua, 2014, Thannoun, 2013 and El-sawy, 2016), while some researchers have found it appropriate to take elevation models (DEM) as input (Abarca, 2006, Alhirmizy, 2015 and Masoud et al., 2011). Various computer-aided lineament extraction programs have been attempted with the availability of digital satellite images. Automatic lineament extraction procedures involve a sort of edge filtering approach. Methods based on automatic lineament extraction algorithms are increasingly used (Raghavan et al., 1995). The various algorithms for automatic lineament extraction have shown their efficiency in the work of several authors (Chavez et al., 1976, Peters et al., 1984, Elrich, 1977, Ochi et al., 1987,
Wang and Howarth, 1990 and Koike et al., 1993). Thus, the LINE (Segment Extraction Algorithm) module of PCI Geomatica and Landsat-8 OLI images were used in the framework of this study to extract lineaments. In fact, the LINE algorithm is based on the Canny contour improvement algorithm (Canny, 1986).

Faced with the interest of lineaments in many areas of life (town planning, hydrogeology, land use planning) and in order to promote a methodology based on parameters of discrimination and evaluation of the precision of the extracted lineaments, it appeared necessary to carry out this study, in order to manipulate the lineaments with precision.

\section{Geographical Situation}

Denguélé District (Figure 1) lies between latitudes $8^{\circ} 28^{\prime} 30^{\prime \prime}$ and $10^{\circ} 21^{\prime} 50^{\prime \prime}$ North and longitudes $8^{\circ}$ $07^{\prime} 40^{\prime \prime}$ and $6^{\circ} 00^{\prime} 15^{\prime \prime}$ West. It covers approximately $20600 \mathrm{~km}^{2}$. Its population is estimated at 289779 inhabitants according to the National Institute of Statistics INS (2014). This District was created by Decree No. 2011-263 of September 28, 2011 on the organization of the national territory into Districts and Regions. It is made up of the Folon region, which includes the departments of Kaniasso and Minignan, and that of Kabadougou, consists of the departments of Odienné, Samatiguila, Madinani, Gbéléban and Séguélon. The map of the administrative boundary of the District of Denguélé comes from the cartographic databases of the National Committee for Remote Sensing and Geographic Information produced in 2012.

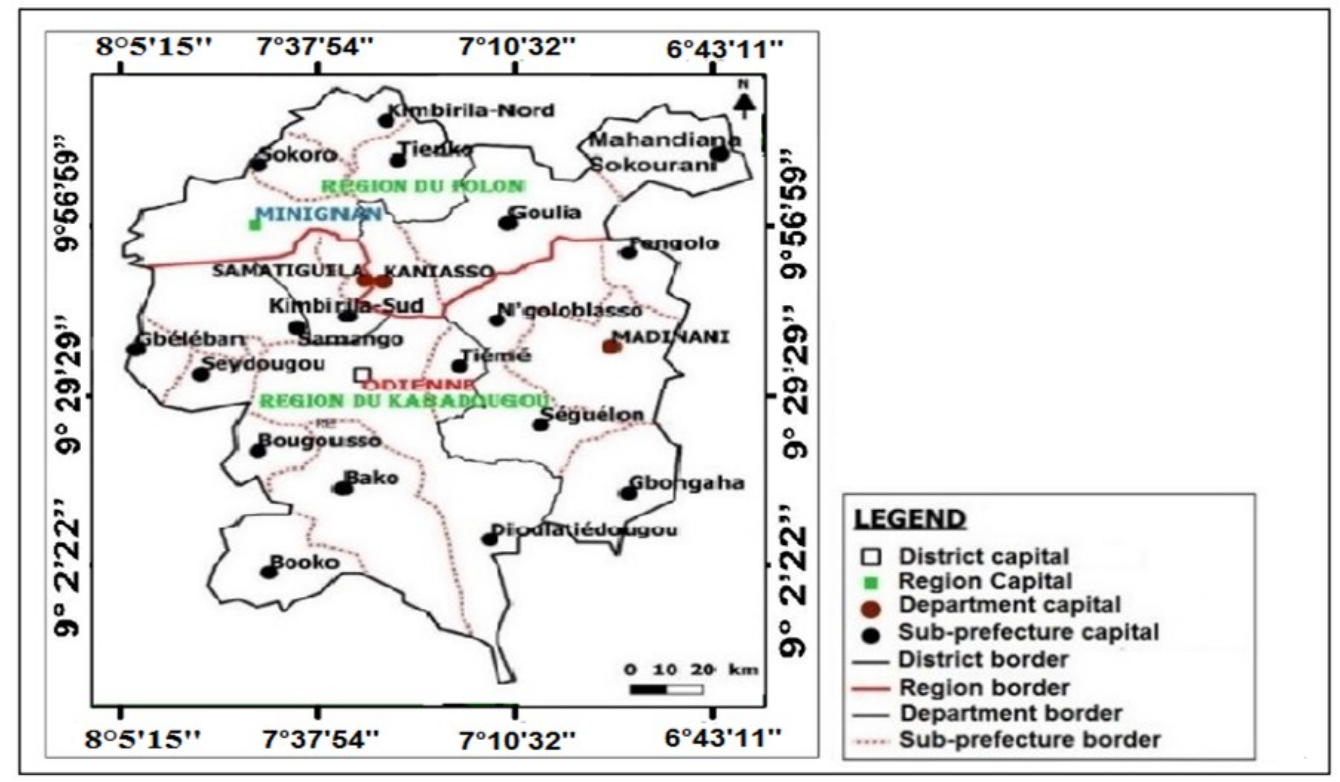

Figure 1: Geological map of the Denguélé District (CNTIG, 2010), modified 
3. Geology

The Ivory Coast is located to the south of the West African craton and its geological past is closely linked to that of the Man Ridge (Tagini, 1971, Papon and Lemarchand, 1973 and Yacé, 1984). The substratum thus formed is essentially Archean in the West and Paleo-Proterozoic in the East and covers $97.5 \%$ of the territory (Leonian-Liberian: 20\%, Eburnean: $77.5 \%)$. The rest of the territory, especially the extreme south, is a sedimentary zone $(2.5 \%)$. Like most of the country which is covered by the crystalline and crystallophyllian substratum, $97.5 \%$ of the whole country, the geological formations of the Denguélé District are essentially substratum. The synthesis of the work carried out in the area by Savané (1997) in Denguélé district, highlights the following distribution: general biotite granites occupy $42 \%$ of the area, migmatites (old and recent) $30 \%$ of the area, granites with homogeneous biotites, granites with two mica and granodiorites occupy $11 \%$, metasediments and metavulcanites represent $5 \%$ and finally gneiss represents $12 \%$ of the area of the District (Figure 2).

\section{Data used in the Study}

The images used for this study are from February 2013, they are Landsat 8 images from paths 198 and 199 and rows 53 and 54 (Table 1). They were acquired between $02 / 01 / 2013$ and $02 / 27 / 2013$, this period corresponds to the dry season, hence the almost total absence of clouds and humidity in the air.

\section{Methodology}

\subsection{Pretreatment}

The techniques of Principal Component Analysis and Directional Filtering were applied to Landsat 8 images, before the implementation of the LINE algorithm.

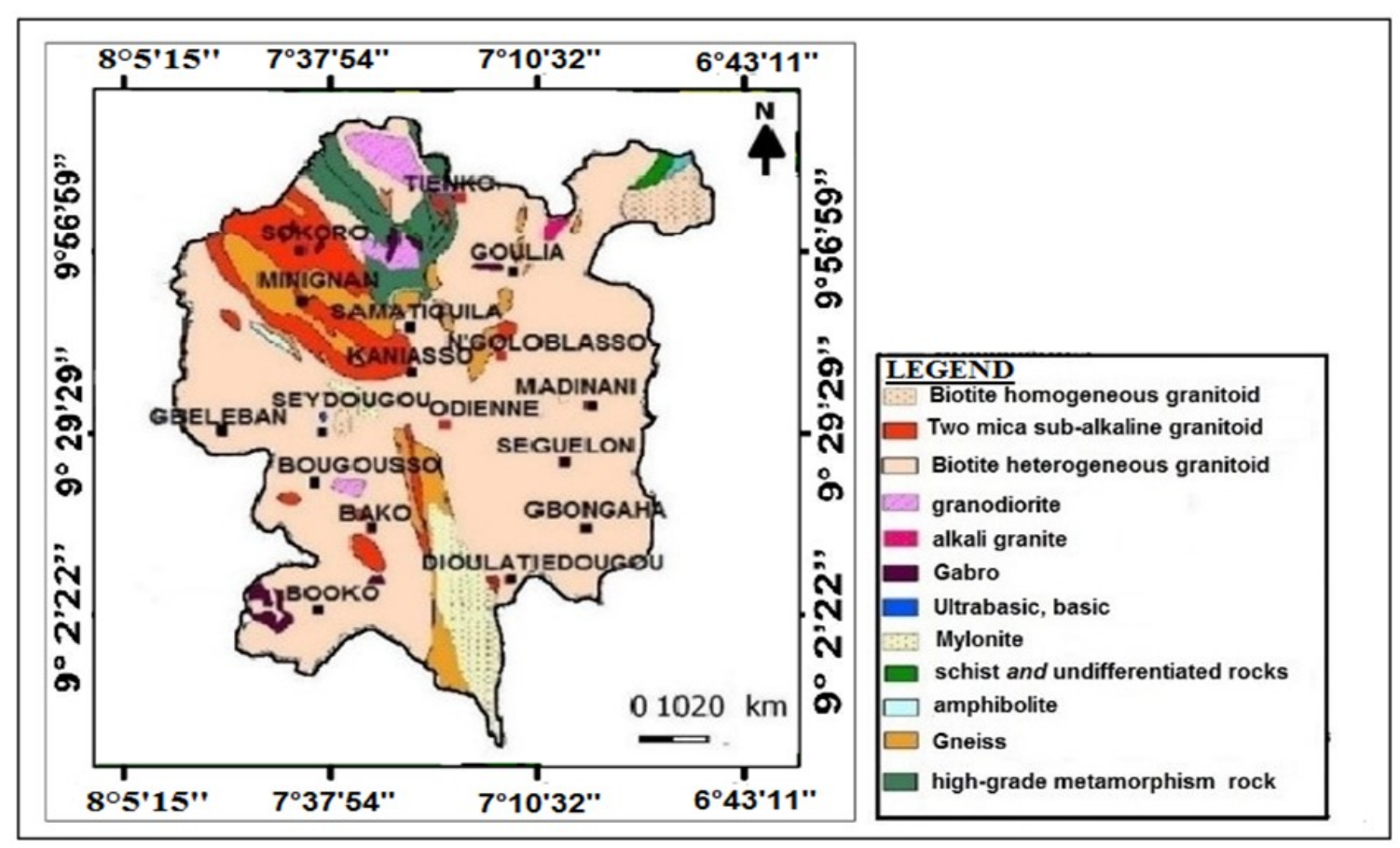

Figure 2: Presentation map of the Denguélé district (CNTIG, 2012)

\begin{tabular}{|l|c|l|l|l|c|}
\hline Sensor & Number of images & Path & Row & Acquisition date & Source \\
\hline \multirow{3}{*}{ Landsat 8} & \multirow{3}{*}{4} & 198 & 53 & February 27, 2013 & \\
& & 198 & 54 & February 27, 2013 & Earth Explorer \\
& & 199 & 53 & February 27, 2013 & (USGS) \\
& & 199 & 54 & February 27, 2013 & \\
\hline
\end{tabular}

Table 1: Characteristics of Landsat 8 images 


\subsection{Principal Component Analysis (PCA)}

Principal Component Analysis (PCA) is a multichannel operation with the aim of improving image quality and eliminating information redundancies. The general approach consists in defining, in the multispectral space, new channels summarizing the information contained in the image. The new decoupled channels thus provide new information. The aim of this technique is to reduce the information contained in several bands that have a strong correlation into a small number of components. These components generally represent $97 \%$ of the overall variation of the original data set and are generally three PCA1, PCA2 and PCA3. PCA1 contains more than two-thirds of the original spectral information and approximates the panchromatic channel (band 8). PCA2 generally emphasizes the opposition between the visible and the infrared that looks like a vegetation index. Rather, PCA3 highlights the differences between the two visible channels. In this study, the i.pca module of the Grass Gis software was used. It takes as input parameters bands $1,2,3,4,5$ and 7 of Landsat 8 images and gives as result a $6 \times 4$ matrix. The 6 rows of this matrix are made up of the components (PCA 1, PCA 2, PCA3, PCA4, PCA5 and PCA 6), the main components PCA1, PCA2, PCA3 being the most significant. The 4 columns are (PCA1, PCA2, PCA3, PCA4, PCA5 and PCA6) (1), the value of these components (2), the eigenvectors (the various coefficients of the matrix) (3) and the percentages of each component (3) with respect to all six bands used.

\subsection{Directional Filtering}

Sobel directional filters ( $7 \mathrm{x} 7$ types) were used to identify lineaments. Indeed, this filter gave interesting results in the work of Jourda (2005) by the optimum enhancement of the first principal (PCA1) component of bands 1, 2,3,4,5 and 7 of Landsat 8 images. They made it possible to better discriminate the lineaments, which facilitated the mapping of lineaments in the Denguélé District. The ENVI sig software was used to apply each convolution matrix of the sobel filter (Figure 3). Thus the filters of directions NS, EW, NW-SE and NE-SW respectively highlight the lineaments of direction EW, NS, NE-SW and NW-SE. Figure 3 shows the different directions applied to the Sobel filter.

\subsection{Application of the LINE Algorithm}

The LINE argorithm is based on the principle of the canny contour detection algorithm, this algorithm (canny contour detection) takes place according to the following steps: (1) Smoothing of input image by Gaussian filtering; (2) Calculation of gradients and modules of gradients; (3) Removal of nonmaximums; (4) Thresholding by hysteresis; (5) Extraction of lineaments. However the LINE algorithm in addition to the traditional steps of the canny algorithm, uses quantitative parameters for evaluation the quality of the input image and for the discrimination of extracted lineaments in order to guarantee their (lineaments) precision. Lineament extraction was performed automatically using GIS software PCI Geomatica 9.1. Indeed, this software uses the LINE Algorithm (Segment Extraction Algorithm).

Sobel NS filter
\begin{tabular}{|c|c|c|c|c|c|c|}
\hline 1 & 2 & 3 & 4 & 3 & 2 & 1 \\
\hline 2 & 3 & 4 & 5 & 4 & 3 & 2 \\
\hline 3 & 4 & 5 & 6 & 5 & 4 & 3 \\
\hline 0 & 0 & 0 & 0 & 0 & 0 & 0 \\
\hline-3 & -4 & -5 & -6 & -5 & -4 & -3 \\
\hline-2 & -3 & -4 & -5 & -4 & -3 & -2 \\
\hline-1 & -2 & -3 & -4 & -3 & -2 & -1 \\
\hline
\end{tabular}

Sobel filter NW-SE

\begin{tabular}{|c|c|c|c|c|c|c|}
\hline 4 & 3 & 3 & 2 & 2 & 1 & 0 \\
\hline 3 & 5 & 4 & 4 & 3 & 0 & -1 \\
\hline 3 & 4 & 6 & 5 & 0 & -3 & -2 \\
\hline 2 & 4 & 5 & 0 & -5 & -4 & -2 \\
\hline 2 & 3 & 0 & -5 & -6 & -4 & -3 \\
\hline 1 & 0 & -3 & -4 & -4 & -5 & -3 \\
\hline 0 & -1 & -2 & -2 & -3 & -3 & -4 \\
\hline
\end{tabular}

Sobel EW

\begin{tabular}{|l|l|l|l|l|l|l|}
\hline 1 & 2 & 3 & 0 & -3 & -2 & -1 \\
\hline 2 & 3 & 4 & 0 & -4 & -3 & -2 \\
\hline 3 & 4 & 5 & 0 & -5 & -4 & -3 \\
\hline 4 & 5 & 6 & 0 & -6 & -5 & -4 \\
\hline 3 & 4 & 5 & 0 & -5 & -4 & -3 \\
\hline 2 & 3 & 4 & 0 & -4 & -3 & -2 \\
\hline-1 & 2 & 3 & 0 & -3 & -2 & -1 \\
\hline
\end{tabular}

Sobel NE-SW

\begin{tabular}{|c|c|c|c|c|c|c|}
\hline 0 & 1 & 2 & 2 & 3 & 3 & 4 \\
\hline-1 & 0 & 3 & 4 & 4 & 5 & 3 \\
\hline-2 & -3 & 0 & 5 & 6 & 4 & 3 \\
\hline-2 & -4 & -5 & 0 & 5 & 4 & 2 \\
\hline-3 & -4 & -6 & -5 & 0 & 3 & 2 \\
\hline-3 & -5 & -4 & -4 & -3 & 0 & 1 \\
\hline-4 & -3 & -3 & -2 & -2 & -1 & 0 \\
\hline
\end{tabular}

Figure 3: The four directions of the sobel filter 
The LINE algorithm was used to extract lineaments in polyline format. Polylines are geographic information data called vectors. Indeed, this algorithm uses the following six (6) parameters: RADI (Radius of the filter), GTHR (Threshold of the contour gradient), LTHR (Threshold of the contour length), FTHR (Threshold of mounting error), ATHR (Angular difference threshold between two contours) and DTHR (Distance chaining threshold to link two contours) (Table 2). The LINE algorithm takes the channel of a single input image (each image filtered according to one of the directions NS, EW, NW-SE and NE-SW). If the input image is 16 -bit or 32 -bit, it is converted to 8 - bit (one byte) using a non-linear graduation routine. As output of the program, we obtain a vector segment which contains the linear functions extracted from the base image. If the database output channel is specified, a binary edge image (which is the result of thresholding) will be saved in the specified channel. The intervals of values taken by the parameters of this algorithm are visible in Table 2. The steps for implementing the line algorithm are illustrated by the diagram below (Figure 4). The figure below shows the steps of the LINE algorithm by using the parameters RADI, GTHR, LTHR, FTHR, ATHR and DTHR contained in the Table 2 above.

\begin{tabular}{|l|c|l|}
\hline \multicolumn{1}{|c|}{ Parameters } & Unit & Values range \\
\hline RADI (Radius of the filter) & Pixels & $0-8192$ \\
\hline GTHR ((Threshold of the contour gradient) & - & $0-255$ \\
\hline LTHR (Threshold of the contour length ) & Pixels & $0-8192$ \\
\hline FTHR (Threshold of mounting error) & Pixels & $0-8192$ \\
\hline ATHR (Angular difference threshold between two contours) & Pixels & $0-90$ \\
\hline DTHR (Distance chaining threshold to link two contours) & Pixels & $0-8192$ \\
\hline
\end{tabular}

Table 2: Parameters of the LINE algorithm

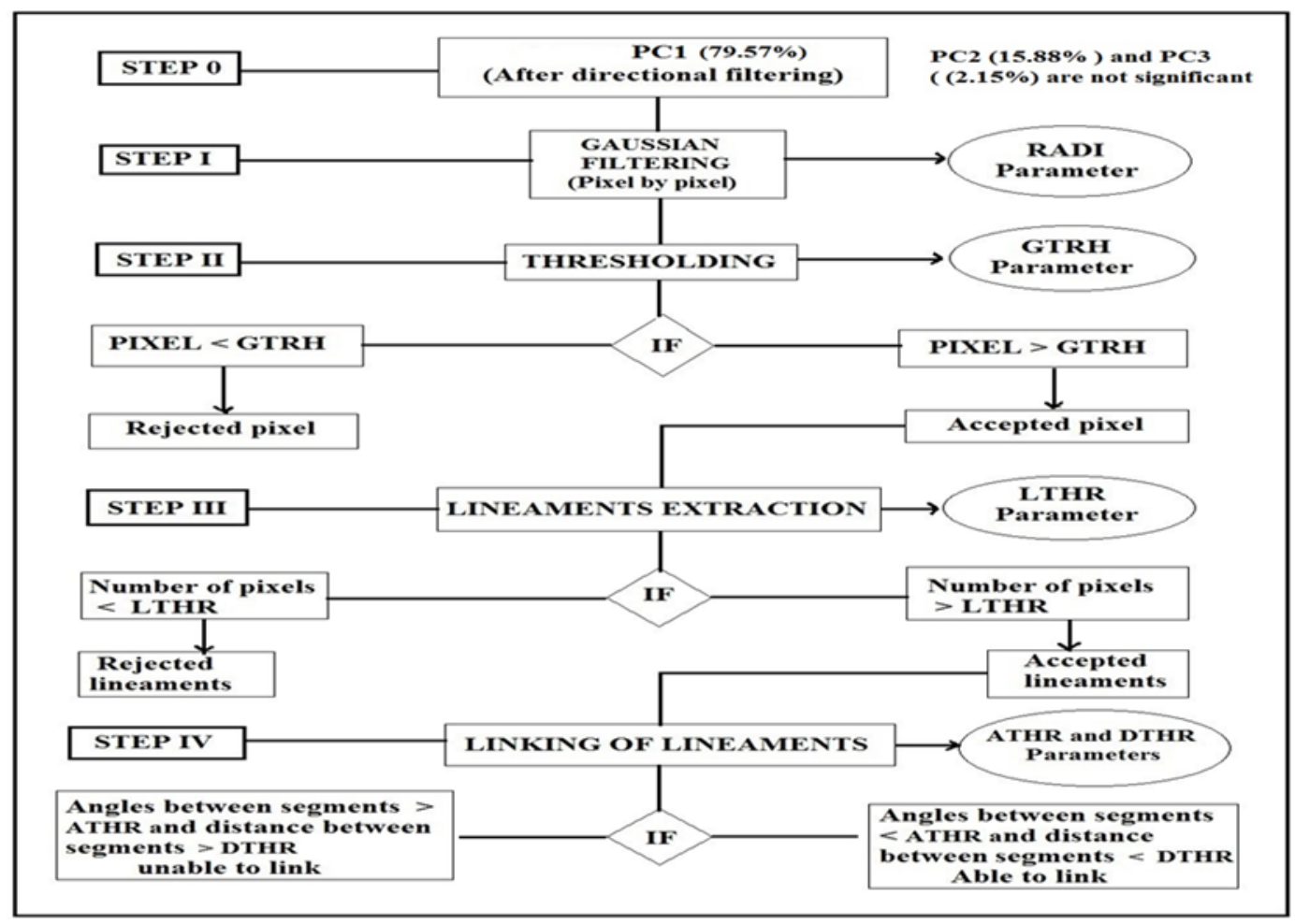

Figure 4: Steps for implementing the LINE algorithm 
Step 1: Gaussian Filtering of the Image using the RADI Parameter

The LINE algorithm is applied to produce an edge intensity image where the input image is filtered by a Gaussian function whose radius is given by the RADI parameter. Note that the higher the value of this parameter, the lower the level of detail and impurities (noise) is in the image. Indeed, the impurities prevent the quality of the outlines extracted from the images. Thus, filtering the input image of the software using the Gaussian function allows to reduce the impurities on it. The filtering of the input image is carried out by multiplying the current pixel, called the initial pixel and the eight pixels which surround it by the values of the filter which correspond to them, then the sum of the various products is carried out and the final result is assigned to the initial pixel. The final result will then be normalized by multiplying it by a coefficient which is the inverse of the sum of the coefficients in the convolution matrix (Gaussian filter). This is done automatically for all cells of the matrix that constitutes the input image, through the use of an algorithmic structure, which is the "for" loop. The image representing Denguélé District having 11111 rows and 11035 columns, the "for" loop has been used for the rows and columns of this image as many times. The filter and the normalization coefficient used for filtering the image representing the study area were used by Colin (2016).

$$
\begin{gathered}
\text { Filter }=\left[\begin{array}{lll}
1 & 2 & 1 \\
2 & 4 & 2 \\
1 & 2 & 1
\end{array}\right] \\
\text { Coefficient }=\frac{1}{\sum_{i, j=1}^{3} a i, j}
\end{gathered}
$$

Equation 1

Equation 2

With: ai, $j$ : The value of row $i$ and column $j$ of the Gaussian filter.

After filtering the image, the gradient of the image was calculated in order to compare the different pixels of the image. The image gradient is calculated by multiplying it by the derivative of the Gaussian filter in the $\mathrm{x}$ and $\mathrm{y}$ directions. This is done automatically using an algorithmic structure, which is the "for" loop. The "for" loop has been used many times for the rows and columns of the image representing the study area. The modulus and normal (angle) of the gradient are then calculated. Thus, for a current pixel of the image, a comparison is Carried out between current pixel and neighboring pixels. For example, if the angle is $90^{\circ}$, the neighboring pixels at the current pixel will have for coordinates $(x, y-1)$ (pixel below the current pixel) and $(x, y+1)$ (pixel above the current pixel). If the value of one neighbor of the current pixel is greater than its value, the value of the current pixel is replaced by 0 , otherwise it keeps its value. The gradient filters and expressions 3 and 4 used by Colin (2016) allowed the calculation of the modulus and the normal of the gradient.

$$
\begin{aligned}
& J_{X}=\left[\begin{array}{lll}
0 & 0 & 0 \\
1 & 0 & 1 \\
0 & 2 & 1
\end{array}\right] \\
& J_{y}=\left[\begin{array}{ccc}
0 & 1 & 0 \\
0 & 0 & 0 \\
0 & -1 & 0
\end{array}\right]
\end{aligned}
$$

Eqaution 3

Eqaution 4

With, Jx : Gradient filter x ; Jy : Gradient filter:

$$
\begin{gathered}
E s(i, j)=\sqrt{J_{X}(i, j)^{2}+J_{Y}(i, j)^{2}} \\
E o(i, j)=\arctan \left(\frac{-J_{y}}{J_{x}}\right)
\end{gathered}
$$

Equation 5

With, Es: Gradient modulus

Eo : Normal gradient

Step 2: Thresholding of the Image using the GTRH Parameter

The edge intensity image is thresholded to obtain a binary image, the threshold is set by the GTRH parameter. It is in fact a question of refining the filtering of the weak contours (linear element) and to keep only the significant contours, using this parameter (GTRH). If the value of a pixel is greater than the threshold, this pixel is naturally kept, this means that it is significant. If the value of the pixel is lower than the threshold parameter, the corresponding pixel will be on the same principle rejected.

\section{Step 3: Extraction of the Curves using the LTHR and FTHR Parameters}

The curves are extracted from the binary contour image. This step is made up of several sub-steps. First, a thinning algorithm is applied to the binary edge image to produce large pixel skeletal contours. Then, a sequence of pixels for each edge is extracted from the image. Any outline with a number of pixels less than the LTHR parameter is rejected. The extracted outline is then converted to a vector shape by connecting the segment pieces. The resulting line is an approximation of the original contour where 
the maximum processing error (distance between two lines) is indicated by the FTHR parameter.

In conclusion, the algorithm connects the pairs of rows that satisfy the criteria.

Step 4: Linking the Linear Segments using the ATHR and DTHR Parameters

Finally, the algorithm links pairs of polylines that satisfy the following two criteria: (1) two different end segments of the two polylines face each other and have a similar orientation, the angle between the two segments must be less than the value specified by ATHR. (2) The two end segments are close to each other, the distance between the end points should be less than the value of DTHR. The table below indicates the values of the 6 parameters of the LINE algorithm used for carrying out this work as suggested by Rayan (2013) (Table 3).

\subsection{Rose Diagram}

The directional analysis of lineaments is made by a rose diagram, it is one of the most used tools among many others to analyze the different directions taken by a two-dimensional phenomenon (Sanderson and Peacock, 2019, Hobbs, 1904, Vasuki et al., 2014 and Chopra et al., 2009). These diagrams are circular ones in which the direction of the vector data is presented in an azimuth class defined as $0^{\circ}$ to $360^{\circ}$, with a common origin and constant frequency. In the same way as it is for common histograms, there is a relation of proportionality between the area and the frequency of each sector of the rose diagram for a given phenomenon analyzed (Nemec, 1988). Within the framework of our study, the rose diagram used for the representation of the direction of lineaments has a frequency of $10^{\circ}$, it was made with Rockworks 12 software.

\section{Results}

\subsection{Principal Component Analysis and Directional Filtering}

Analysis of the principal components PCA1, PCA2 and PCA 3 of bands 1, 2, 3, 4, 5 and 7 of the Landsat 8 images shows that they contain respectively 79.57 ; 15.88 and $2.15 \%$, this represents $97.6 \%$ overall of all channels. The convolution matrices of the directional filters of Sobel in the four directions NS, EW, NE-SW and NW-SE (Figures 5, 6, 7 and 8) made it possible to achieve the enhancement of the first principal component (PCA1) which represents $97.6 \%$ of all the channels.

Table 3: Values of the parameters used during the study as suggested by Rayan (2013)

\begin{tabular}{|l|l|}
\hline \multicolumn{1}{|c|}{ Parameters } & Parameters values \\
\hline RADI (Radius of the filter) & 5 \\
\hline GTHR ((Threshold of the contour gradient) & 60 \\
\hline LTHR (Threshold length) & 10 \\
\hline FTHR (Threshold of mounting error) & 20 \\
\hline ATHR (Angular difference threshold) & 2 \\
\hline DTHR (Distance chaining threshold) & 1 \\
\hline
\end{tabular}

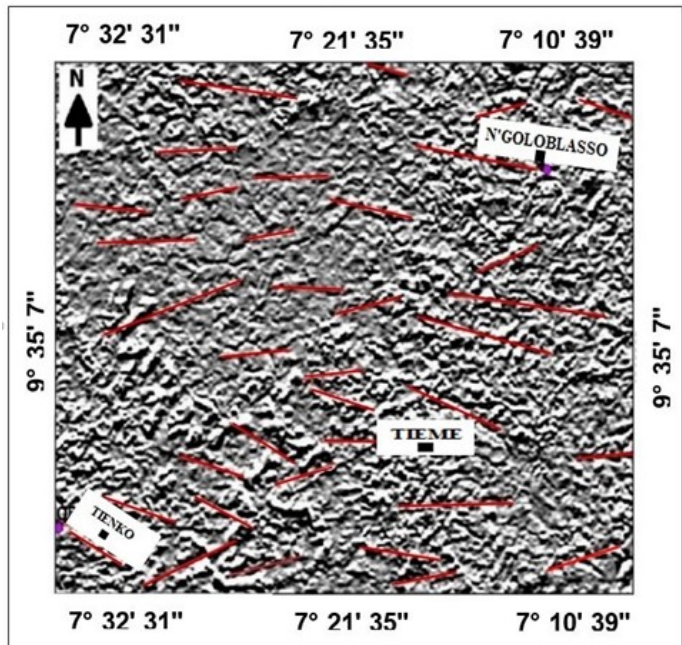

Figure 5: NS direction Sobel filter

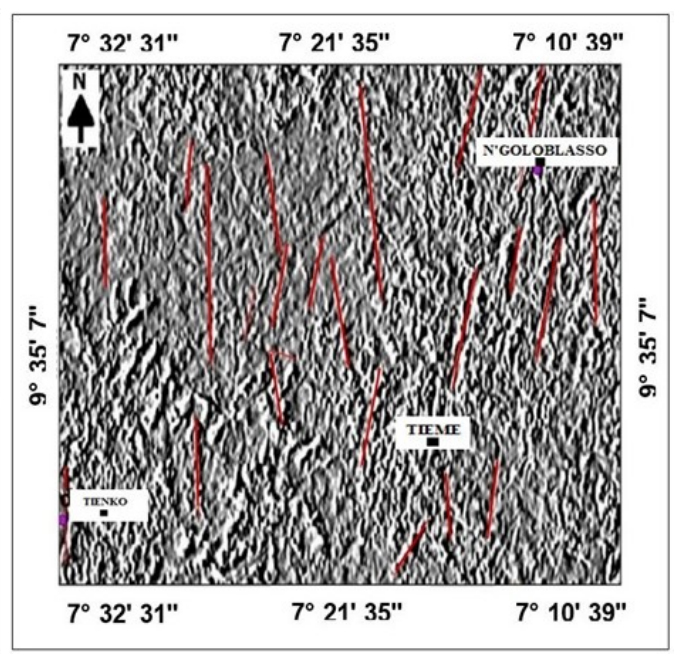

Figure 6: EW direction Sobel 


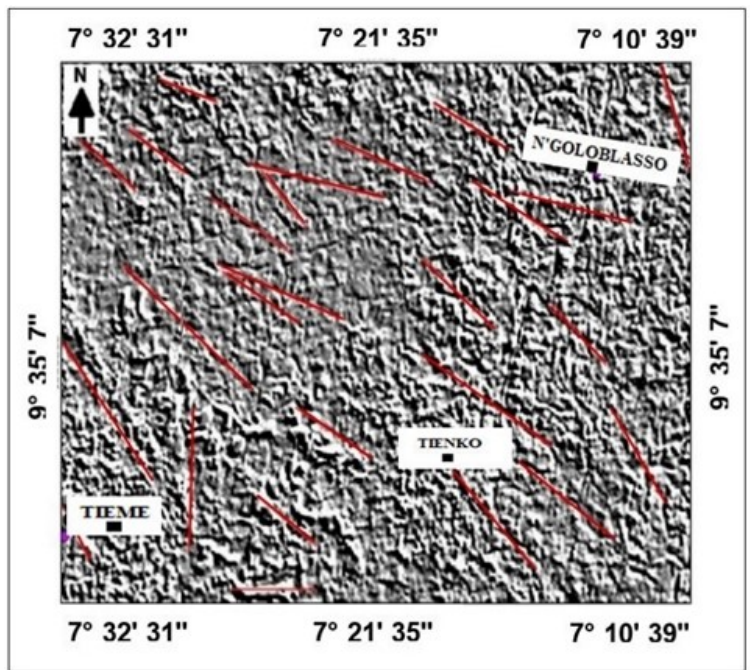

Figure 7: Sobel filter for NE-SW direction

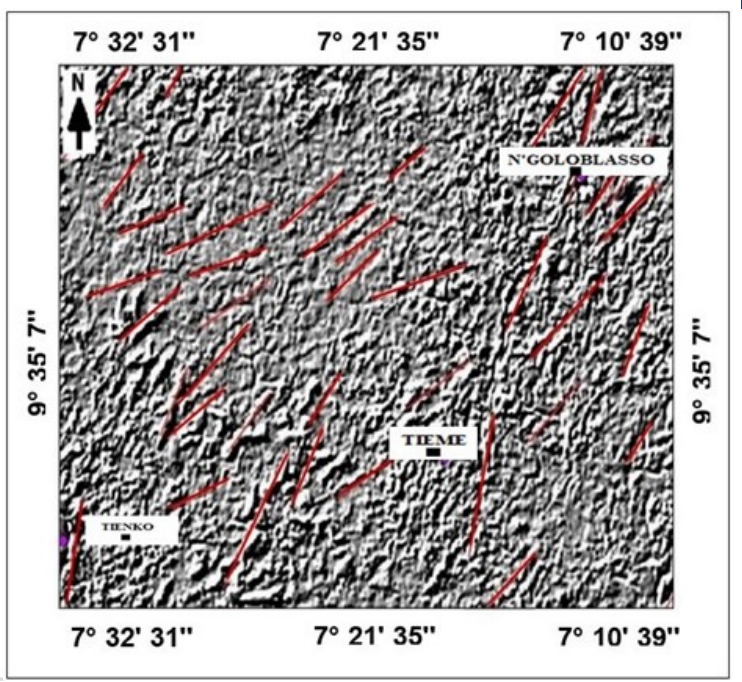

Figure 8: Sobel filter for NW-SE direction

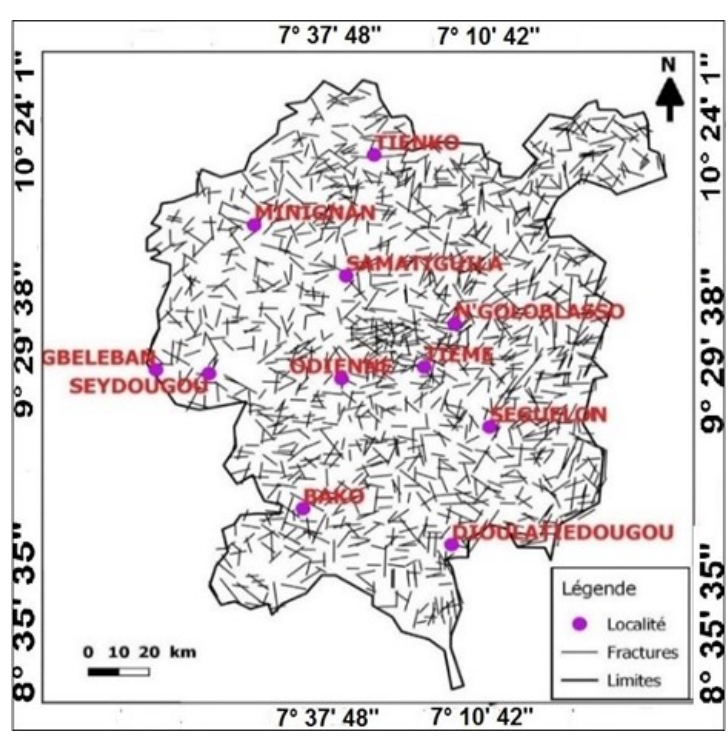

Figure 9: Detailed lineaments map

Indeed, the sobel filter groups together the 18 lineament families in four directions, the NS direction groups the $\mathrm{N} 80^{\circ}-90^{\circ} / \mathrm{N} 260^{\circ}-270^{\circ}$ and $\mathrm{N} 90^{\circ}-100^{\circ} / \mathrm{N} 270^{\circ}-280^{\circ}$ families ( 2 families), the E$\mathrm{W}$ direction groups the $\mathrm{N} 170^{\circ}-180^{\circ} / \mathrm{N} 350^{\circ}-360^{\circ}$ and $\mathrm{N} 0^{\circ}-10^{\circ} / \mathrm{N} 180^{\circ}-190^{\circ}$ families ( 2 families), the $\mathrm{NE}-\mathrm{SW}$ direction includes the $\mathrm{N} 10^{\circ}-\mathrm{N} 20^{\circ} / \mathrm{N} 190^{\circ}$ $200^{\circ} ; \quad \mathrm{N} 20^{\circ}-30^{\circ} / \mathrm{N} 200^{\circ}-210^{\circ} ; \quad \mathrm{N} 30^{\circ}-40^{\circ} / \mathrm{N} 21^{\circ} 0-$ $220^{\circ} ; \quad \mathrm{N} 40^{\circ}-50^{\circ} / \mathrm{N} 220^{\circ}-230^{\circ} ; \quad \mathrm{N} 50^{\circ}-60^{\circ} / \mathrm{N} 230^{\circ}-$ $240^{\circ}$; $\mathrm{N} 60^{\circ}-70^{\circ} / \mathrm{N} 240^{\circ}-250^{\circ}$ and $\mathrm{N} 70^{\circ}-80^{\circ} / \mathrm{N} 250^{\circ}$ $260^{\circ}$ families ( 7 families). Finally, the NW-SE direction is that of the $\mathrm{N} 100^{\circ}-110^{\circ} / \mathrm{N} 280^{\circ}-290^{\circ}$; $110^{\circ}-120^{\circ} / \mathrm{N} 290^{\circ}-300^{\circ} ; \quad \mathrm{N} 120^{\circ}-130^{\circ} / \mathrm{N} 300^{\circ}-310^{\circ}$; $\mathrm{N} 130^{\circ}-140^{\circ} / \mathrm{N} 310^{\circ}-320^{\circ} ; \mathrm{N} 140^{\circ}-150^{\circ} / \mathrm{N} 320^{\circ}-330^{\circ}$; $\mathrm{N} 150^{\circ}-160^{\circ} / \mathrm{N} 330^{\circ}-340^{\circ}$ and $\mathrm{N} 160^{\circ}-170^{\circ} / \mathrm{N} 340^{\circ}-$ $350^{\circ}$ families (7 families). Applying LINE

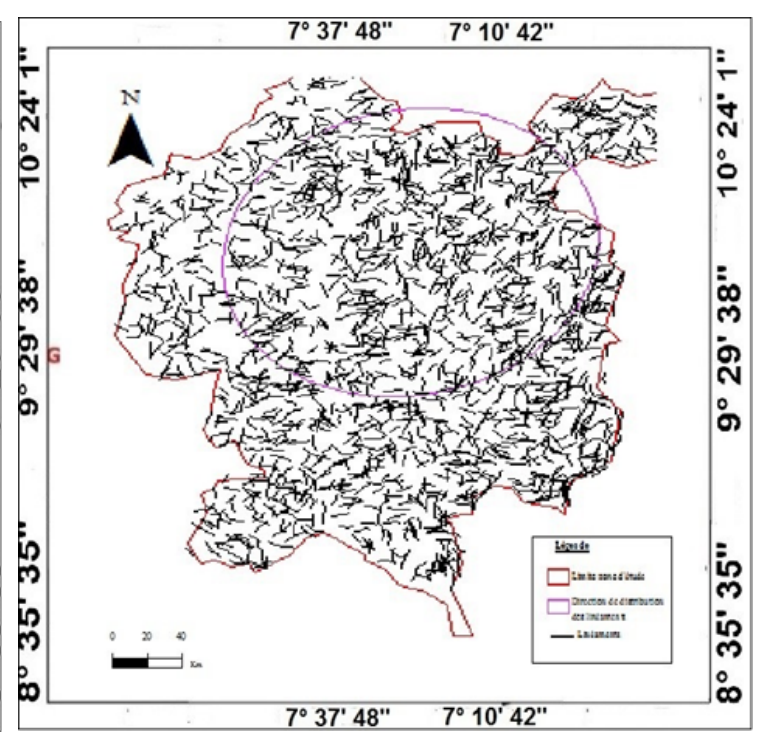

Figure 10: Dominant directions NE-SW map

Algorithm (Segment Extraction Algorithm), for automatic lineament extraction gives the results as shown in Figures 5, 6, 7 and 8. The NS, EW, NWSE and NE-SW filters highlight respectively lineaments of EW, NS, NE-SW and NW-SE directions.

\subsection{Detailed Linear Map}

After validation of the lineaments, the detailed lineament map (Figures 9, 10) was obtained by merging the lineaments obtained by automatic extraction in the four different directions (NS, NESW, EW and NW-SE). Table 3 summarizes the numbers of lineaments by direction.

The map in Figure 9 contains more than 3468 lineaments. The minimum and maximum lengths of 
these segments are respectively $4201.08 \mathrm{~m}$ and $16167.59 \mathrm{~m}$ and their cumulative length is $18919517.9 \mathrm{~m}$. The average lineament lengths are $5.55 \mathrm{~km} ; 5.75 \mathrm{~km} ; 5.6 \mathrm{~km}$ and $5.40 \mathrm{~km}$ respectively for NE-SW, NS, EW and NW-SE directions. The distribution of lineaments according to the four tectonic directions is as follows, the NE-SW, EW, NW-SE and NS directions represent respectively $31.83 \%$ (1104 lineaments ); $28.71 \%$ (996 lineaments ); 20.18\% (700 lineaments ) and 27.91\% (968 lineaments ) of all lineaments (Table 4).

\subsection{Directional Analysis of Lineaments}

The analysis of the direction of the lineaments using a rose diagram with $10^{\circ}$ of frequency (Figure 11), shows that the dominant directions are NE-SW (31.83\%), EW (28.71\%) and NS (27.91\%) (Figure 11 , marked in red). The most important families of these directions are represented by the inclination lineaments $\mathrm{N} 70^{\circ}-80^{\circ}$ corresponding respectively to the NE-SW direction, $\mathrm{N}^{\circ}-10^{\circ}$ for the $\mathrm{EW}$ direction and $\mathrm{N} 80^{\circ}-90^{\circ}$ for the NS direction (Figure 11).

\subsection{Statistical Analysis of Lengths}

The analysis of the lineaments made it possible to represent their distribution as a function of the length, this representation (Figure 12) shows an inverse evolution between the length of the lineaments and their spatial distribution. In fact, the longer lineaments are, the lower their frequency of presence is. This situation is the same for the four directions N-S, E-W, NE-SW and NW-SE. The lineaments have lengths that vary between 4201.1 and $16167.6 \mathrm{~m} ; 4201.7$ and $14550.09 \mathrm{~m} ; 4201.6$ and $14697.29 \mathrm{~m}$ and 4211.4 and $12447.59 \mathrm{~m}$ respectively for the N-S, E-W, NE-SW and NW-SE directions (Table 5).

Table 4: Number of lineaments by direction

\begin{tabular}{|l|l|l|}
\hline Directions & Number & Average Lengths (Km) \\
\hline NE-SW & 1104 & 5.55 \\
\hline NS & 968 & 5.75 \\
\hline EW & 996 & 5.60 \\
\hline NW-SE & 700 & 5.40 \\
\hline Fusion & 3468 & 5.59 \\
\hline
\end{tabular}

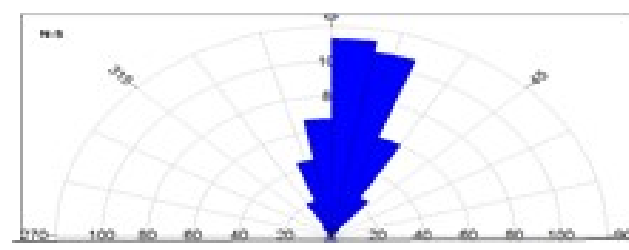

Linéaments de direction NS

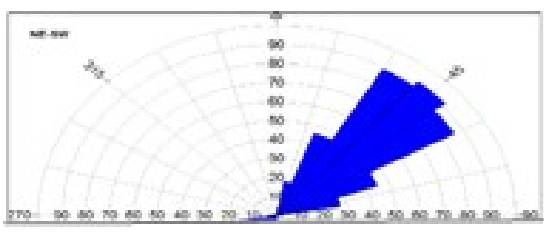

Linéaments de direction NE-SW

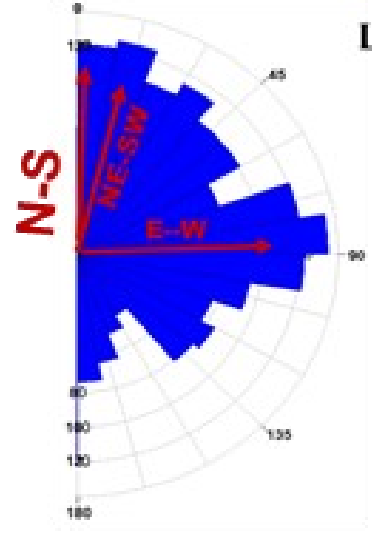

\section{Linéaments de direction $\mathbf{E W}$}

Figure 11: Rose diagrams of lineaments directions

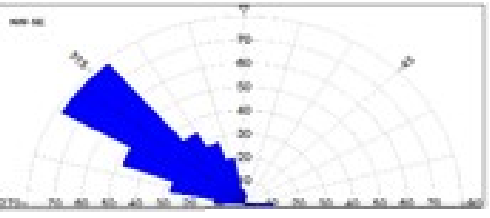

Linéaments de direction NW-SE

= 
Table 5: Lineament lengths by direction

\begin{tabular}{|l|c|l|l|}
\hline Directions & Min length (m) & Max length (m) & Average Lengths (m) \\
\hline NE-SW & 4201.60 & 14697.29 & 5550 \\
\hline NS & 4201.10 & 16167.60 & 5750 \\
\hline EW & 4201.70 & 14550.09 & 5600 \\
\hline NW-SE & 4211.40 & 12447.59 & 5400 \\
\hline Fusion & 4201.10 & 15378.40 & 5590 \\
\hline
\end{tabular}

Table 6: Lineaments precision parameters

\begin{tabular}{|l|l|l|l|l|}
\hline \multirow{2}{*}{ Directions } & \multirow{2}{*}{ Std.standard (Km) } & \multicolumn{2}{|c|}{ Confidence Interval } & \multirow{2}{*}{ R-mag } \\
\cline { 3 - 4 } & & Value & Percentage & \\
\hline NE-SW & 4.36 & $\mathbf{3 . 1}^{\circ}$ & $95 \%$ & 0.85 \\
\hline NS & 4.4 & $3.1^{\circ}$ & $95 \%$ & 0.84 \\
\hline EW & 4.69 & $2.8^{\circ}$ & $95 \%$ & 0.86 \\
\hline NW-SE & 4 & $3.94^{\circ}$ & $95 \%$ & 0.8 \\
\hline
\end{tabular}

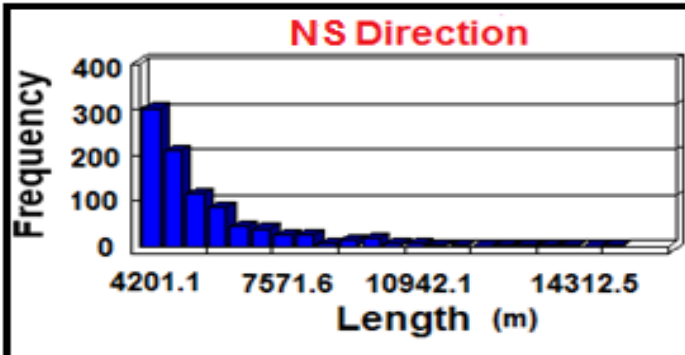

Spatial distribution of lineaments (NS direction)

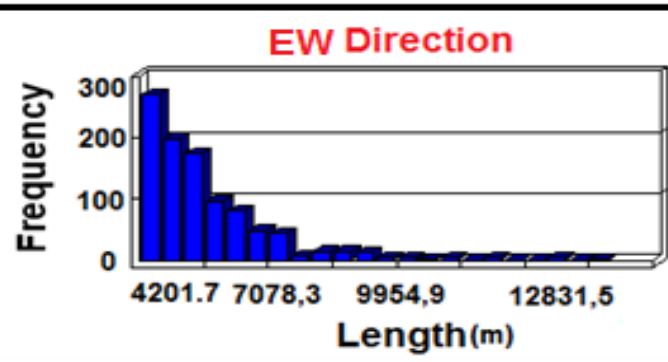

Spatial distribution of lineaments (EW direction)

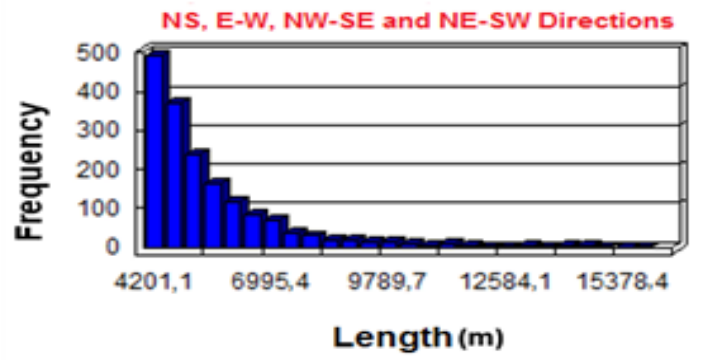

Spatial distribution of lineaments

(NS, EW, NW-SE and NE-SW direction)

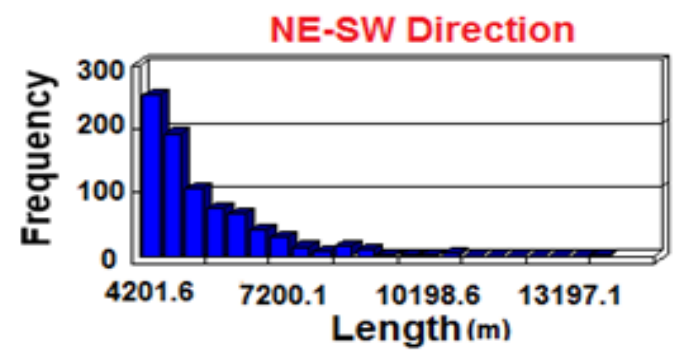

Spatial distribution of lineaments (NE-SW direction)

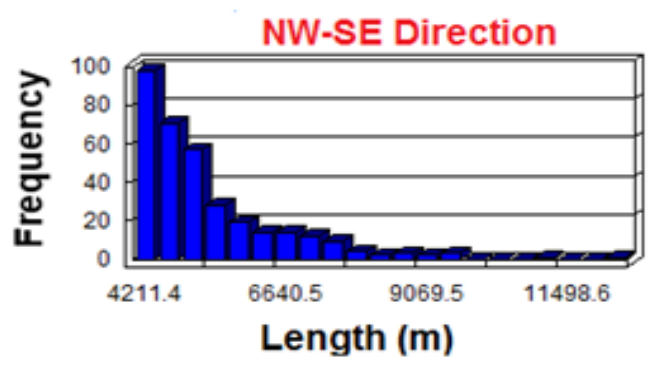

Spatial distribution of lineaments (NW-SE direction)

Figure 12: Spatial distribution of lineaments (N-S, E-W, NE-SW and NW-SE directions) 


\subsection{Evaluation of the Precision of the Extracted} Lineaments

The standard deviations of the lengths of the lineaments materialized on the rose diagram are respectively $4.36 \mathrm{Km}, 4.4 \mathrm{Km}, 4.69 \mathrm{Km}$ and $4.5 \mathrm{Km}$ (Table 6) for the directions NE-SW, NS, EW and $\mathrm{NW}$-SE, these values are approximately equal with average values of lineament lengths in these same directions $5.55 \mathrm{Km}, 5.75 \mathrm{Km}, 5.60 \mathrm{Km}$ and 5.40 $\mathrm{Km}$ (Table 5), this shows a weak dispersion of the lengths of the lineaments estimated on the rose diagram. The dispersion indices measured by the Rmag parameter are respectively $0.85,0.84,0.86$ and 0.8 (Table 6) respectively for the directions NE-SW, NS, EW and NW-SE. These values (R-mag) are close to one, which justifies the proximity between the value of the standard deviations and the mean lengths of the lineaments which materializes the low dispersion of the lengths of extracted lineaments. Because the higher the dispersion index, the more the quantities studied here the lengths of the lineaments are not dispersed. The confidence thresholds of the lineaments extracted in the four directions NE-SW, NS, EW and NW-SE are 95\% (Table 6) which gives an error level of $5 \%$ on the precision of the lineaments extracted in the four directions. This margin of error is scientifically acceptable, and shows the precision of lineaments extracted using the LINE algorithm.

\subsection{Distribution of Lineaments Density}

The spatial distribution map of the lineaments density (Figure 13) shows a spatial variation in the intensity of lineaments. This lineaments density map shows a distribution of lineaments over the entire territory of the Denguélé District. Indeed, the analysis of the different proportions of the lineaments density classes shows that the medium and high density classes represent $85 \%$ of the area of the Denguélé District. The low density class represents $10 \%$ of the study area. This class is found in the localities of Seydougou, Gbéléban, Minignan and Tiémé. Finally, the zones of very high lineaments densities only constitute traces. They are made up of small portions of surfaces scattered over the territory of the District.

\section{Discussion}

The analysis of the principal components PCA1, PCA2 and PCA3 gives respectively $79.57 \%$; $15.88 \%$ and $2.15 \%$, this represents $97.6 \%$ overall of all channels. These different proportions, in particular that of ACP1 (79.57\%) show that this component is significant and representative of the information provided by the other main components.

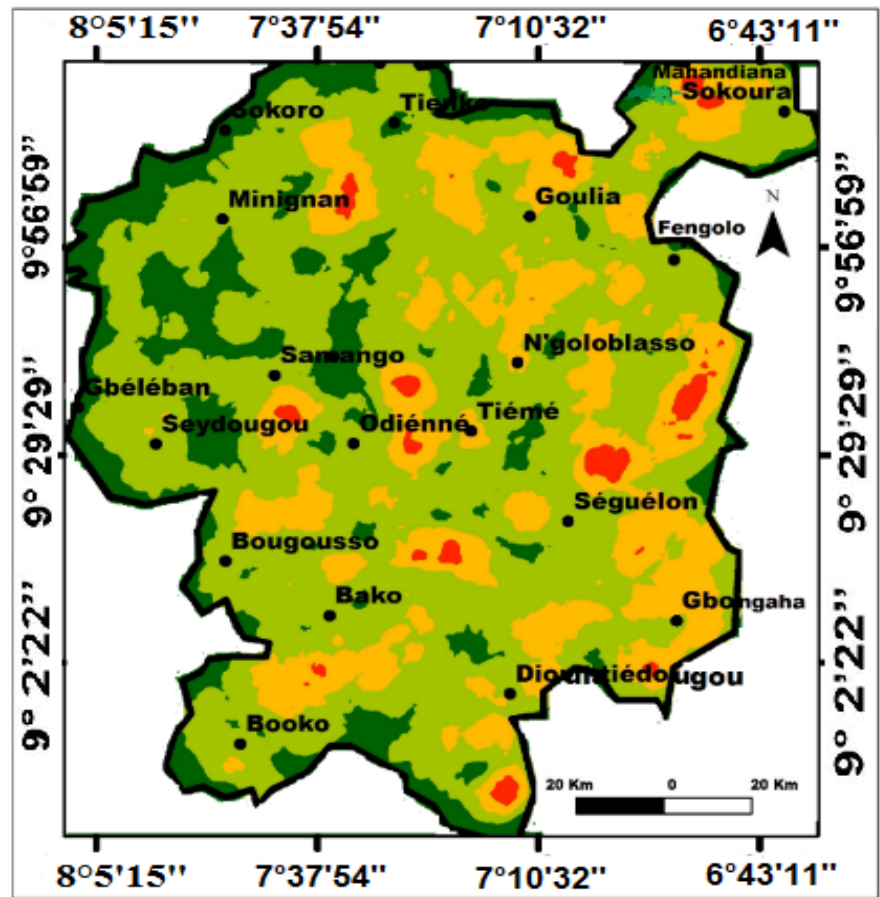

\section{LEGEND}

Fracturing density

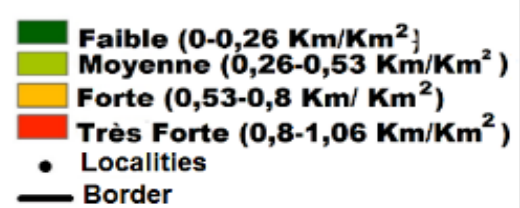

Figure 13: Map of fracturing densities in Denguélé District 
The directional filters applied to the first principal component made it possible to extract the lineaments in the following proportions: the directions NE-SW, E-W, NW-SE and N-S respectively represent $31.83 \% ; 28.71 \% ; 20.18 \%$ and $27.91 \%$ of all lineaments. The dominant directions are NESW (31.83\%), E-W (28.71\%) and N-S $(27.91 \%)$. The most important families of these directions are represented by the lineaments inclination angles $\mathrm{N} 70^{\circ}-80$ for the NE-SW direction, $\mathrm{N} 0^{\circ}-10^{\circ}$ for the $\mathrm{E}-\mathrm{W}$ direction and $\mathrm{N} 80^{\circ}$ $90^{\circ}$ for the N-S direction, respectively. The NE-SW (Birimian) direction is that taken by a major fault in the Denguélé district, in this case the N'goloblasso fault. The automatic lineament extraction method made it possible to extract a large number of lineaments quickly and methodically. Indeed, the approach used based on the LINE algorithm uses parameters for improving the quality of the input image (RADI) and lineament discrimination (GTRH, LTHR and FTHR). This algorithm avoided manual extraction of lineaments, which is a tedious operation. It also made it possible to confirm the results obtained on the same area by previous work with more diligence, therefore it can be used concomitantly or replace previous methods (manual extraction of lineaments). The proportions (97.6\%) of the principal components obtained are in accordance with the results of Ranjbar et al., (2004). According to this author, these principal components generally represent $97 \%$ of all original data. The dominant direction (NE-SW with $31.83 \%$ of the lineaments) of lineaments in the Denguélé is in accordance with that of Savané (1997) who found that $(30.70 \%)$ of high flow structures are linked to this direction. However, the E-W direction (28.71\%) is also significant, but not interesting because the E$\mathrm{W}$ direction fractures over the area are waterproof according to Kouadio (2005). The importance of the fracturing of the granitoids (biotite granitoids of general extension which occupy $42 \%$ of the surface area) which globally cover the Denguélé district is an indicator of good groundwater potential in the District. Indeed, according to N'Go et al., (2005), granites constitute generally very productive lithological formations (N'Go et al., 2005 and Shankar and Mohan, 2006). Algorithmic lineament extraction methods have been used for lineament extraction by many authors (Chavez et al., 1976, Peters et al., 1984, Elrich, 1977, Ochi et al., 1987, Wang and Howarth, 1990 and Koike et al., 1993). In this study, it was a question of optimizing the extraction of lineaments. The use of algorithmic methods gives effective results. The use of the LINE algorithm based on the canny edge detection algorithm has shown a rigorous scientific approach based on evaluation parameters of the extraction process that are parameters for improving the quality of the input image (RADI) and lineament discrimination (GTRH, LTHR and FTHR).

\section{Conclusion}

In this study, it was a question of optimizing the extraction of lineaments. The use of algorithmic methods gives effective results. The use of the LINE algorithm based on the canny edge detection algorithm has shown a rigorous scientific approach based on evaluation parameters of the extraction process that are parameters for improving the quality of the input image (RADI) and lineament discrimination (GTRH, LTHR and FTHR). 3468 lineaments were extracted in this study. The minimum and maximum lengths of these lineaments are respectively $4201.08 \mathrm{~m}$ and $16167.59 \mathrm{~m}$ and their cumulative length is $18919517.9 \mathrm{~m}$. the dominant directions are NE-SW (31.83\%), EW $(28.71 \%)$ and NS (27.91\%). the analysis of the different proportions of the lineaments density classes shows that the medium and high density classes represent $85 \%$ of the area of the Denguélé District, this proportion shows a this proportion of lineament density shows good groundwater potential in the Denguélé district.

\section{References}

Abarca, E., Vazquez-Sune, E., Carrera, J., Capino, B., Gamez, D. and Batlle, F., 2006, Optimal Design of Measures to Correct Seawater Intrusion. Water Resour. Res., Vol. 42(9), https://doi.org/10.1029/2005WR004524.

Alhirmizy, S., 2015, Automatic Mapping of Lineaments using Shaded Relief Images Derived from Digital Elevation Model (DEM) in Kirkuk Northeast Iraq. Internat. Jour. Sci. Res., Vol. 4(5), 2228-2233.

Canny, J. F., 1986, A Computational Approach to edge detection. IEEE Trans. on Pattern Analysis and Machine Intelligence, Vol. 8, 679-714.

Chavez, P. S., Berlin, G. L. and Acosta, A. V.,1976, Computer Processing of Landsat MSS Digital Data for Linear Enhancement. Proc. 2nd Annual W.T. Pecora Memorial Symposium, Sioux Falls, South Dakota: Falls Church ,Virginia. 235 - 250.

Chopra, A. K., Chakresh, P. and Prasad, G., 2009. Scenario of Heavy Metal Contamination in Agricultural Soil and its Management. Journal of Applied and Natural Science, Vol. 1(1), 99108. 
CNTIG- Centre National de Télédétection et d'Information Géographique, 2012, Carte Administrative de la Côte d'Ivoire à échelle 1: 200000. http://cntig.net/index.php/a-propos.

Colin, L., 2016, Détection des Contours d'une Image: Filtre de Canny, ENSAT Informatique, Multimédia et Réseaux, 1-12. URL https://colinleverger.fr/assets/projects/.

Elrich, R. W., 1977, Detection of Global Edges in Textured Images. IEEE Trans. on Computers, Vol. 26(6), 235-250.

El-sawy, E. K., Ibrahim, A. M., El-bastawesy, M. A. and El-saud, W. A., 2016, Automated, Manual Lineaments Extraction and Geospatial Analysis for Cairo-Suez District (Northeastern CairoEgypt), using Remote Sensing and GIS. Internat. Jour. Innovative Sci., Engg. and Tech., Vol. 3(5), 491-500.

Hobbs, W. H., 1904, Lineaments of the Atlantic Border Region, Geological Society. American Bulletin, Vol. 15(1), 483-506.

Ibrahim, U. and Mutua, F., 2014, Lineament Extraction Using Landsat 8 (OLI) in Gedo, Somalia. Internat. Jour. Sci. Res., Vol. 3(9), 291-296.

INS-Institut National de la Statistique, 2014, Recensement Général de la Population et de l'Habitat, 22p. ULR http://www.ins.ci/ (Site visité le 12/09/ 2016).

Jourda, J. P., 2005, Méthodologie d'application des techniques de Télédétection et des systèmes d'information géographique à l'étude des aquifères fissurés d'Afrique de l'Ouest. Concept de l'hydrotechnique spatiale : cas des zones tests de la Côte d'Ivoire, Thèse de Doctorat d'Etat, Université de Cocody, 1-430.

Koike, K., Nagano, S. and Ohimi, M., 1993, Development and Application of Lineament Extraction Method using Segment Tracing Algorithm, Geoinformatics, Tokyo University, $19-20$.

Kouadio, K. E., 2005, Stratégie de prospection des nappes de fissures par Analyse spatiale du potentiel de productivité et optimisation de la profondeur des forages. Cas du Denguélé (NordOuest de la Côte d'Ivoire). Thèse de Doctorat, Université de Cocody, Abidjan, 1-181.

Masoud, A. A. and Koike, K., 2011, Auto-Detection and Integration of Tectonically Significant Lineaments from SRTM DEM and Remotely Sensed Geophysical Data. ISPRS Jour. Photogrametry and Remote Sensing, Vol. 66(6), 818-832.
Morris, K., 1991, Using Knowledge-Base Rules to Map the Three Dimensional Nature of Geologic Features. Photogrammetric Engineering and Remote Sensing, Vol.57(9), 1209-1216.

Nemec, W., 1988, The Shape of the Rose. Sed Geol, Vol. 59(1-2), 149-152.

N'Go, Y. A., Goné, D. L., Savané, I. and Goblé, M. M., 2005, Potentialités en eaux souterraines des aquifères fissurés de la région d'Agboville (SudOuest de la Côte d'Ivoire): Caractérisation hydroclimatique et physique. Afrique SCIENCE, Vol. 1, 127-14.

O’Leary, D. W., Friedman, J. D. and Pohn, H. A., 1976, Lineament, Linear, Lineation: Some Proposed New Standards for Old Terms. Geological Society America Bulletin, Vol. 87, 1463-1469.

Ochi, M., Komai, J., Arai, K., Fujuoka, H., Tokuo, T. and Wadatsumi, K.,1987, Photogeological Appraisal of Automatically Extracted Lineaments from Landsat Data. Mining Geology, Vol. 37(2), 99-108.

Papon, A. and Lemarchand, R., 1973, Géologie et minéralisation du Sud-Ouest de la Côte d'Ivoire. Synthèse des travaux de l'opération SASCA 1962-1968. Mémoire B.R.G.M., Vol. 80, 1-284.

Peters, D. C., Speirer, R. A. and Moll, S. H., 1984, Image Processing for Automatic Lineaments Analysis, Computers in Geology, 88 - 91.

Prasad, A. D., Jain, K. and Gairola, A., 2013, Mapping of Lineaments and Knowledge Base Preparation using Geomatics Techniques for Part of the Godavari and Tapi basins, India: A Case Study. Internat. Jour. Computer Applications, Vol. 70(9), 39-47.

Raghavan, V., Masumoto, S., Koike, K. and Nagano, S., 1995, Automatic Lineament Extraction from Digital Images Using a Segment Tracing Algorithm and Rotation Transformation Approach. Compurers \& Geosciences, Vol. 21(4), 555-591.

Ranjbar, H., Honarmand, M. and Moezifar, Z., 2004, Applicationof the Crosta Technique for Porphyry Copper Alteration Map-Ping, using ETM+ Data in the Southern Part of the Iranian Vol-Canic Sedimentary Belt. J. Asian Earth Sci., Vol. 24(2), 237-243.

Rayan, G. T., 2013, Automatic Extraction and Geospatial Analysis of Lineaments and their Tectonic Significance in some areas of Northern Iraq using Remote Sensing Techniques and GIS, Remote Sensing Center / Mosul University, Iraq, International Journal of Enhanced Research in Science and Technology and Engineering, Vol. 2(2), 1-11. 
Shankar, R. M. N. and Mohan, G., 2006, Assessment of the Groundwater Potential and Quality in the Bhatsa and Kalu River Basins of Thane District, Western Deccan Volcanic Provence of India. Environmental Geology, Vol. 49(7), 990-998.

Sanderson, D. J. and Peacock, D. C. P., 2019, Making Rose Diagrams Fit-For-Purpose, EarthScience Reviews, 201, DOI: 10.1016/J.Earscirev.2019.103055.

Savané, I., 1997, Contribution à l'étude géologique et hydrogéologique des aquifères discontinus du socle cristallin d'Odienné Nord-Ouest de la Côte d'Ivoire). Apports de la télédétection et d'un Système d'Information Hydrogéologique à Référence Spatiale. Thèse de doctorat ès Sciences Naturelles, Université d'Abidjan- Côte d'Ivoire, $386 \mathrm{p}$.

Stefouli, M., Angellopoulos A., Perantonis S, Vassilas, N., Ambazis, N. and Charou, E., 1996, Integrated Analysis and use of Remotely Sensed Data for the Seismic Risk Assessment of the Southwest Peloponessus Greece. First Congress of the Balkan Geophysical Society, 23-27 September, Athens Greece.
Tagini, B., 1971, Esquisse Structural de la Côte d'Ivoire. Essaie de géotechnique régionale. Thèse de Doctorat, Université de losanne, Suisse, 1-302.

Thannoun, R. G., 2013, Automatic Extraction and Geospatial Analysis of Lineaments and their Tectonic Significance in Some Areas of Northern Iraq using Remote Sensing Techniques and GIS. Internat. Jour. Enhanced Res. Sci. Tech. Engg., Vol. 2(2), 1-11.

Vasuki, Y., Eun-Jung, H., Kovesi, P. and Micklethwaite, S., 2014, Semi-automatic Mapping of Geological Structures using UAVbased Photogrammetric Data: An Image Analysis Approach. Computers \& Geosciences, Vol. 69, 22-32, DOI:10.1016/j.cageo.2014.04.012

Wang, J. and Howorth, P. J., 1990, Use of Hough Transform in Automated Lineament Detection. IEEE Trans. Gescience and Remote Sensing, Vol. 28(4), 561 - 566.

Yacé, I., 1984, Le précambrien de l'Afrique de l'ouest et ses corrélation avec le Brésil orientale. Rapport final, Publication PICG-CIFEG, Paris, $1-28$. 